\title{
Synthesis of didodecylmethyl hydroxyl sulfobetaine and its evaluation for alkali-free flooding
}

\author{
Changxin Shi $\cdot$ Shemin Song $\cdot$ Hongmei Ren $\cdot$ \\ Qingqiao Zen $\cdot$ Xianrong Tang
}

Received: 21 July 2014/ Accepted: 17 November 2014/Published online: 5 December 2014

(C) The Author(s) 2014. This article is published with open access at Springerlink.com

\begin{abstract}
In this paper, didodecylmethyl hydroxyl sulfobetaine was synthesized by reaction of didodecylmethyl amine with sodium 2-hydroxy-3-chloro propanesulfate. The interfacial tensions between Dagang crude oil and solution of the surfactants, solution of surfactant-polymer mixtures were measured. The effects of surfactant concentration and aging time on the interfacial tension were investigated. It is found that the synthesized betaine surfactant could reduce the interfacial tension to ultra-low without alkali, alcohol and the other additives in the absence of or presence of polymer. The surfactant-polymer system could lower the interfacial tension to ultra-low, even was aged for more than 2 weeks. The sand-pack flooding tests indicated that, with $0.2 \mathrm{wt} \%$ of the betaine and with $1,500 \mathrm{mg} / \mathrm{L}$ of polymer, $16.89 \%$ of an additional OOIP (original oil in place) was recovered from a sand pack. This result suggested that the didodecylmethyl hydroxyl sulfobetaine might be a good surfactant candidate for enhanced oil recovery.
\end{abstract}

Keywords Synthesis - Didodecylmethyl hydroxyl sulfobetaine $\cdot$ Alkali-free $\cdot$ Ultra-low interfacial tension

\section{Introduction}

The chemical method of enhanced oil recovery using surfactants has been studied for many years (Johnson 1957;

C. Shi $(\bowtie) \cdot$ H. Ren $\cdot$ Q. Zen $\cdot$ X. Tang

Exploration and Development Research Institute of Huabei

Oilfield Company, Renqiu, Hebei 062552, China

e-mail: cxshi@qq.com

S. Song

Development Department of Huabei Oilfield Company,

Renqiu, Hebei 062552, China
Scott et al. 1965; Hill and Reisberg 1973). Surfactant often used together with alkali, or alkali and polymer in oil recovery (Deborah and Philip 1990; Ball and Surkalo 1990; Kang et al. 2000; Samanta et al. 2010). The reason is that the reaction between the alkali and naphthenic acids in the crude oil could generate soap; the soap and the added surfactants usually showed synergistic effects in reducing the interfacial tension (Rudin and Wasan 1992). On the other hand, the addition of the alkali could reduce the adsorption of the surfactant, sequester divalent ions, and alter wettability (Hirasak et al. 2011). However, the presence of alkali in the flooding systems also caused several problems. Strong alkali such as $\mathrm{NaOH}$ and $\mathrm{NaSiO}_{4}$ could cause permeability reduction and formation damage (Bagci et al. 2000). Scaling formation is another disadvantage of flood using the conventional alkalis, which often leads to the shortening of pump detection period (Krumrine et al. 1985; Cheng et al. 2008). A new alkali, sodium metaborate, was reported that no scaling formed, but it could decrease the viscosity of polymer (Flaaten et al.2010; Hou et al. 2005), and was not a good option for brines with high bicarbonate and sulfate concentrations (Gupta et al. 2009). The addition of the organic alkali has no influence on the polymer viscosity, but it is not a cheap additive (Berger et al. 2006).

Due to the problems mentioned above, several surfactant-polymer flooding free of alkali pilot tests have been carried out in some China's oil fields, such as Shengli, Dagang and Henan (Zhu et al. 2012). The key for the surfactant-polymer flooding is to find a well-performed surfactant that could reduce the interfacial tension between oil and water to ultra-low values. Many researchers tried to use mixed surfactants including: petroleum sulfonate formulations (Xiong et al. 2009), alkanolamide mixtures (Meng et al. 2010), alkanolamide with petroleum sulfonate ( $\mathrm{Li}$ et al. 
2010), Span with alkyl polyglycoside (Iglauer et al. 2004), mixed polyoxypropylene ether sulfates (Shinoda and Shibata 1986), etc. In recent years, betaine-type surfactants have received extensive attention in the field of petroleum industry for its excellent water solubility, high foam stability, and good hard water resistance. Also it is not sensitive to temperature, $\mathrm{pH}$, and electrolyte variation ( $\mathrm{Qu}$ et al. 2011). There have been some reports on its laboratory experiment on oil recovery, showing good results ( $\mathrm{Li}$ et al. 2012; Yu et al. 2011; Feng et al. 2012).Some of them used betaine surfactant mixtures (Cui et al. 2012;Zhao et al. 2012). The main disadvantage of using mixed surfactant is that chromatographic separation may occur in practical application, which will affect the oil recovery (Miller et al. 1991).

In this paper, we synthesized the didodecylmethyl hydroxyl sulfobetaine using didodecylmethyl amine and sodium 2-hydroxy-3-chloro propanesulfate. The test results show that this product is an excellent surfactant for surfactant-polymer flooding.

\section{Materials and methods}

\section{Materials}

Didodecylmethyl amine of $95 \%$ purity was obtained from Rhodia Feixiang Chemicals Co. Ltd., China. Sodium 2-hydroxy-3-chloro propanesulfate of $99 \%$ purity was purchased from Fuertai Chemicals Co. Ltd., China. Ethanol and sodium hydroxide (AR grade) were purchased from Sinopharm Chemical Reagent Beijing Co. Ltd. Hydrolyzed polyacrylamide (HPAM) with a degree of hydrolysis of $28 \%$ was supplied by Dagang Bohong Petroleum Chemical Company. The molecular weight of the HPAM is $2.5 \times 10^{7}$. The reservoir water was used during the experiment. The content of total dissolved solids is $13,454 \mathrm{mg} / \mathrm{L}$; the water contained $350 \mathrm{mg} / \mathrm{L}$ calcium ion and $180 \mathrm{mg} / \mathrm{L}$ magnesium ion. The crude oil was offered from the third block of Dagang oilfield Gangxi area in China.

Experimental section

\section{Synthesis}

The didodecylmethyl amine $23 \mathrm{~g}(0.06 \mathrm{~mol})$ was taken in a $250 \mathrm{ml}$ three-neck flask. $15.88 \mathrm{~g}(0.08 \mathrm{~mol})$ of sodium 3-chloro-2-hydroxypropanesulphonate was first dissolved in $120 \mathrm{ml}$ isopropanol-water (1:1 by volume) solution, and then put into the flask. The reaction mixture was stirred for $18 \mathrm{~h}$ at $70{ }^{\circ} \mathrm{C}$ under reflux and $3.2 \mathrm{~g}$ of sodium hydroxide dissolved in $20 \mathrm{~mL}$ of water was added drop by drop. The mixture was separated by standing, and the lower layer was washed three times with petroleum ether.
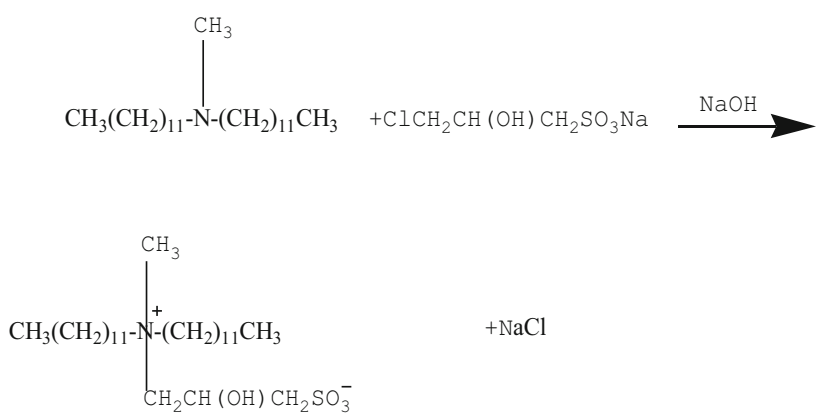

Scheme 1 Synthesis of didodecylmethyl hydroxyl sulfobetaine

After evaporation of the water and alcohol to dryness, the obtained solid was dissolved in hot ethanol, followed by immediate filtration. After evaporation of the ethanol, the final product was obtained. The synthetic route for the surfactant is depicted in Scheme 1.

\section{Methods}

Measurement of FT-IR spectra was performed on a Nicolet 8700 FT-IR spectrometer using $\mathrm{KBr}$ pellets.

MS analysis was carried out with a Waters Quattro Premier XE. The capillary voltage was $3.5 \mathrm{kV}$, the source temperature was $110{ }^{\circ} \mathrm{C}$, the desolvation temperature was $350{ }^{\circ} \mathrm{C}$, the cone voltage was $5 \mathrm{~V}$ and the collision energy was $15 \mathrm{eV}$.

Measurements of the interfacial tension were made by the spinning drop technique at $53.2{ }^{\circ} \mathrm{C}$ using a Dataphysics interfacial tensiometer.

To investigate the thermal stability of the surfactantpolymer system, the prepared surfactant-polymer solutions $(0.2 \%$ of surfactant and $1,500 \mathrm{mg} / \mathrm{L}$ of polymer) were put into sealed glass tubes; the glass tubes were maintained at $53.2{ }^{\circ} \mathrm{C}$. Took a tube out, and measured the interfacial tension between oil and solutions.

Core flood experiment was conducted on the above sand packed core. The core was first filled with the Dagang crude oil sample, and then flooded with water until water cut was more than $98 \%$. Next, $0.3 \mathrm{PV}$ of oil displacement agents was injected. The flooding system velocity was $0.2 \mathrm{~mL} / \mathrm{min}$ at the reservoir temperature of $53.2^{\circ} \mathrm{C}$. After the oil displacement agent flooding, water was injected until water cut was more than $98 \%$.

\section{Results and discussion}

Characterization of the product

\section{Infrared spectroscopy}

The infrared spectrum of the synthesized is shown in Fig. 1. It can be seen that the absorption at 2,969, 2,926, 
Fig. 1 FT-IR spectrum of the didodecylmethyl hydroxyl sulfobetaine

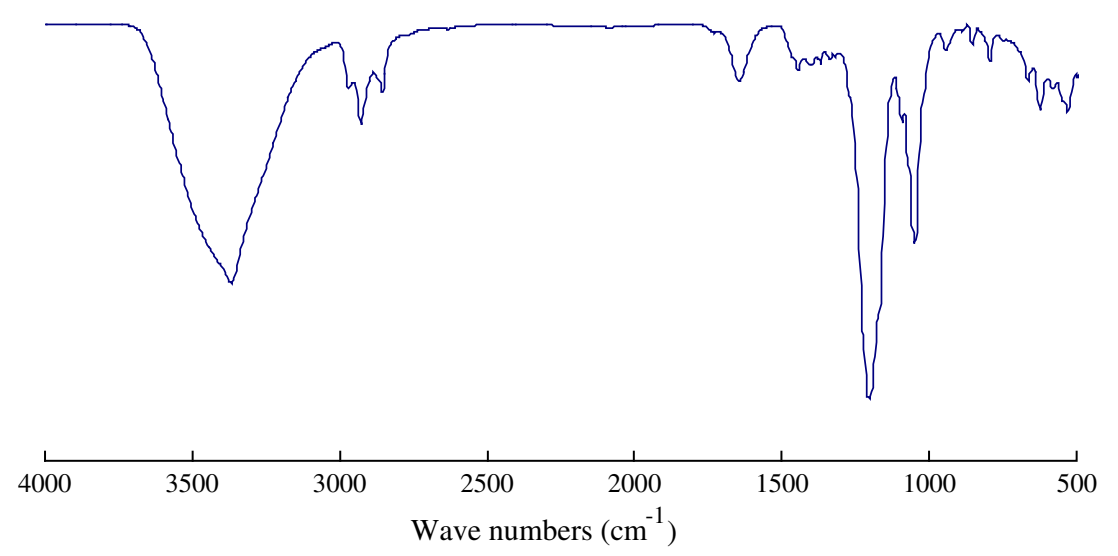

2,856 and $1,367 \mathrm{~cm}^{-1}$ can be ascribed to the stretching vibrations of alkyl groups. The stretching vibration at $3,367 \mathrm{~cm}^{-1}$ corresponds to the $\mathrm{OH}$ group in the product. The absorption at $1,645 \mathrm{~cm}^{-1}$ can be assigned to the deformation vibration of the $\mathrm{OH}$ group. A strong absorption appeared at $1,204 \mathrm{~cm}^{-1}$ attributes to a $\mathrm{C}-\mathrm{O}$ stretching vibration. The absorption at $1,048 \mathrm{~cm}^{-1}$ is due to the presence of the $\mathrm{SO}_{3}{ }^{-}$stretching vibration. The absorption at $624 \mathrm{~cm}^{-1}$ represents the $\mathrm{S}-\mathrm{O}$ stretching vibration.

\section{ESI-MS spectrum}

The product was analyzed by ESI-MS in negative mode. The spectrum is shown in Fig. 2.

The peaks at $\mathrm{m} / \mathrm{z}=137.1$ correspond to $\left[\mathrm{CH}_{2}-\mathrm{CH}\right.$ $\left.(\mathrm{OH})-\mathrm{CH}_{2}-\mathrm{SO}_{3}\right]^{-}$, the peak at $\mathrm{m} / \mathrm{z}=155.3$ may correspond to $\left[\mathrm{CH}_{2}-\mathrm{CH}(\mathrm{OH})-\mathrm{CH}_{2}-\mathrm{SO}_{3}+\mathrm{H}_{2} \mathrm{O}\right]^{-}$, the peak at $\mathrm{m} / \mathrm{z}=197.2$ corresponds to $\left[\mathrm{C}_{12} \mathrm{H}_{25}-\mathrm{N}-\mathrm{CH}_{3}\right]^{-}$, the peak at $m / z=337.5$ corresponds to $\left[\mathrm{C}_{12} \mathrm{H}_{25}-\mathrm{N}\left(\mathrm{CH}_{3}\right)-\mathrm{CH}_{2}-\mathrm{CH}\right.$ $\left.(\mathrm{OH})-\mathrm{CH}_{2}-\mathrm{SO}_{3}\right]^{-}$, and the peak at $\mathrm{m} / \mathrm{z}=478.4$ may correspond to $\left[\mathrm{C}_{12} \mathrm{H}_{25}-\mathrm{N} \quad\left(\mathrm{CH}_{3}\right)-\mathrm{CH}_{2}-\mathrm{CH} \quad(\mathrm{OH})-\mathrm{CH}_{2}-\right.$ $\left.\mathrm{SO}_{3}+\mathrm{H}_{2} \mathrm{O}\right]^{-}$. The ion at $\mathrm{m} / z 460.5$ is may due to the didodecylmethyl hydroxyl sulfobetaine losses of 44 ($\mathrm{CH}_{2}-\mathrm{CH}_{2}-\mathrm{CH}_{3}$ ). The peak at $\mathrm{m} / \mathrm{z}=520.6$ corresponds to $\left[\left(\mathrm{C}_{12} \mathrm{H}_{25}\right)_{2}-\mathrm{N}\left(\mathrm{CH}_{3}\right)-\mathrm{CH}_{2}-\mathrm{CH}(\mathrm{OH})-\mathrm{CH}_{2}-\mathrm{SO}_{3}+\mathrm{CH}_{3}\right]^{-}$.

Measurement of Interfacial Tensions

In the surfactant flooding systems for enhanced oil recovery, the interfacial tension between crude oil and reservoir water should be lower than $10^{-2} \mathrm{mN} \mathrm{m}^{-1}$ (Aoudia et al. 2006). Furthermore, in order to improve sweep efficiency in the reservoir, polymer was often added to the surfactant solutions, which requires that the interfacial tension
Fig. 2 MS spectrum of the didodecylmethyl hydroxyl sulfobetaine

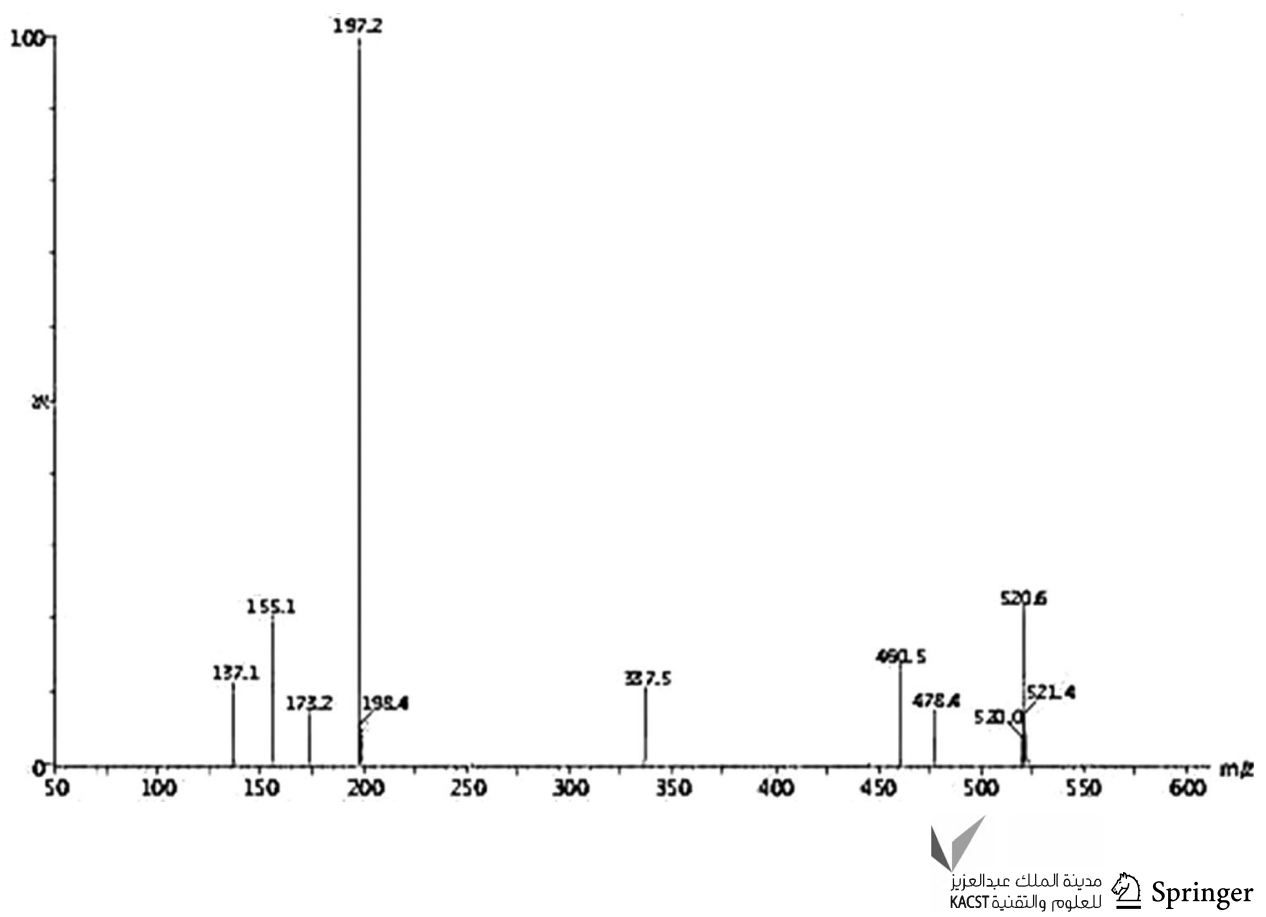


Fig. 3 Effects of didodecylmethyl hydroxyl sulfobetaine concentration on the interfacial tension at $53.2{ }^{\circ} \mathrm{C}$ between Dagang crude oil and reservoir water

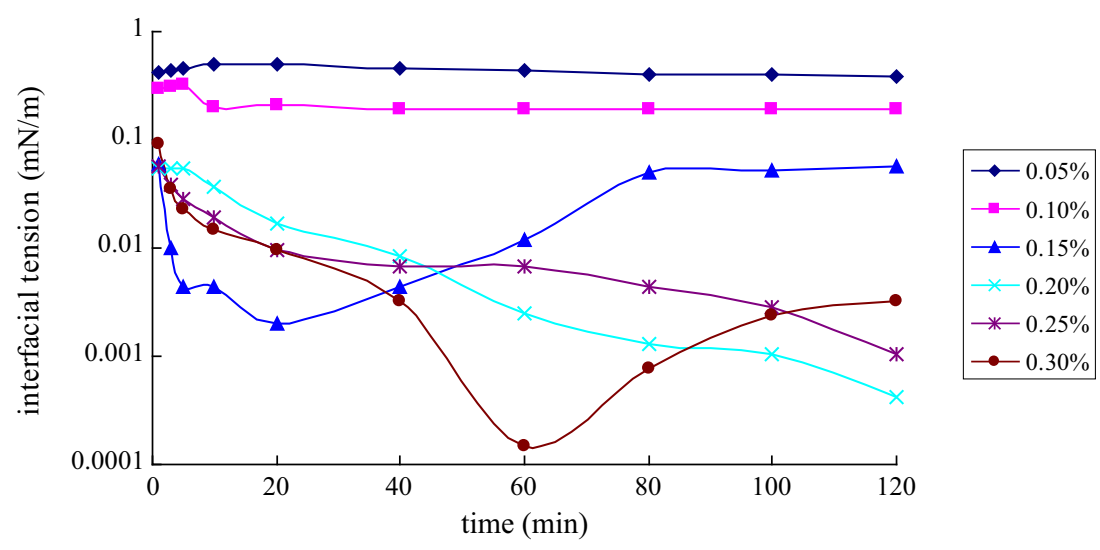

between the crude oil and surfactant-polymer solutions should also be below than $10^{-2} \mathrm{mN} \mathrm{M}^{-1}$. Generally speaking, time, surfactant concentration, temperature and salinity have effects on the interfacial tension. However, in the practical application, the temperature and salinity are fixed in the reservoir. Here, the effects of time and surfactant concentration on the interfacial tension were investigated. The dynamic interfacial tension between Dagang crude oil and reservoir water is shown in Fig. 3.

As shown in Fig. 3, the interfacial tension can reach the ultra-low value (less than $10^{-2} \mathrm{mN} \mathrm{m}^{-1}$ ) at a concentration range, from 0.15 to $0.3 \mathrm{wt} \%$. The commonly used surfactant concentration range in the oil recovery process is $0.05-0.3 \%$. The lowest interfacial tension value is $1.45 \times 10^{-4} \mathrm{mN} \mathrm{m}^{-1}$, corresponding to the surfactant concentration of $0.3 \%$. Ultra-low interfacial tension value can only last for about 45 min when the surfactant concentration is $0.15 \%$. In view of adsorption of the surfactant on the rock and economic factors, the optimum concentration is $0.2 \%$. The presence of polymer in the surfactant solution often has effects on the interfacial tension. To compare with that in the absence of polymer, the HPAM is added to the betaine solution (the concentration is $0.2 \%$ ), and the concentration of the HPAM in solution is $1,500 \mathrm{mg} / \mathrm{L}$. The effects of polymer on the interfacial tension are presented in Fig. 4.

Figure 4 shows that in the presence of polymer, the interfacial tension can also be reduced to ultra-low values. But it takes a longer time to reach the ultra-low values when the polymer existed. This is because the presence of polymer increases the viscosity of the solution, which slows the surfactant transfer rate at the interface; another reason might be that the added polymer forms an aggregate with the surfactant, which results in a variation of the surfactant concentration and then affects the interfacial tension. For the surfactant-polymer system, the interfacial tension decreases rapidly at the early times. The reason may be due to uneven distribution of the surfactant in the system.

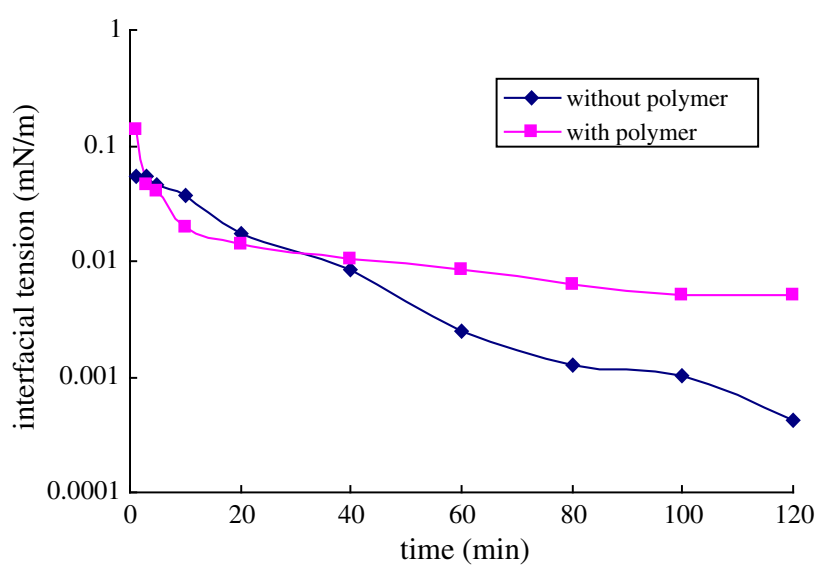

Fig. 4 Effects of polymer on the interfacial tension

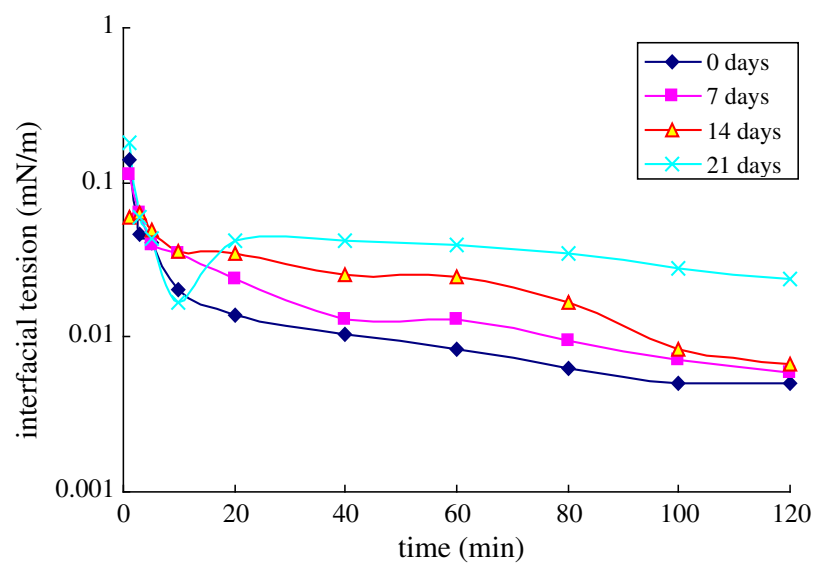

Fig. 5 Dynamic interfacial tension values at different aging time

In the oil production process, after the injection of the surfactant-polymer system into the formation, it often takes some time for the system to take effects. During this period, the polymer degradation will speed up because of high temperature and the existence of oxygen and bacteria. Moreover, another explanation is: system entropy and confusion degree increase with time. The disorder of the 
Table 1 Oil displacement test of surfactant, polymer and binary system

\begin{tabular}{|c|c|c|c|c|c|c|c|c|}
\hline No. & Length & Diameter & $\begin{array}{l}\text { Core permeability } \\
(\mathrm{mD})\end{array}$ & $\begin{array}{l}\text { Porosity } \\
(\%)\end{array}$ & $\begin{array}{l}\text { Crude oil saturation } \\
(\%)\end{array}$ & $\begin{array}{l}\text { Recovery of water } \\
\text { flooding }(\%)\end{array}$ & $\begin{array}{l}\text { Additional } \\
\text { recovery }(\%)\end{array}$ & $\begin{array}{l}\text { Total recovery } \\
(\%)\end{array}$ \\
\hline 1 & 30 & 1.95 & 932 & 30.28 & 63.78 & 46.32 & 10.38 & 56.70 \\
\hline 2 & 30 & 1.95 & 906 & 31.45 & 64.72 & 45.93 & 3.79 & 49.42 \\
\hline 3 & 30 & 1.95 & 943 & 32.59 & 63.25 & 45.18 & 16.89 & 62.07 \\
\hline
\end{tabular}

surfactant distribution at the oil-water interface is aggravated, which will cause vibration of the interfacial tension (Li et al. 2009). So the thermal stability of the system has to be investigated to make sure that the surfactant-polymer is effective during flooding period. The results are presented in Fig. 5.

As can be seen from Fig. 5, the surfactant-polymer system can reduce the interfacial tension to ultra low at least within 14 days. The interfacial tension gradually increases with passing days. In the 21 st day, the interfacial tension is above $10^{-2} \mathrm{mN} \mathrm{m}^{-1}$. For the surfactant-polymer system, the variation of surfactant concentration and viscosity loss of the polymer are jointly responsible for the interfacial tension changes.

\section{Sand-pack core flood tests}

The core flood test results are given in Table 1 .

According to Table 1, $16.89 \%$ additional oil is produced by injecting 0.3 pore volume of the surfactantpolymer solution, making the total recovery rate reach $62.07 \%$. However, under the same experimental conditions, only $10.38 \%$ of the additional oil can be recovered by polymer flooding and $3.79 \%$ for the surfactant flooding. It appears to be a synergistic effect between the surfactant and the polymer combination flooding, resulting in a higher oil recovery than the sum of the single polymer and surfactant flooding. This showed the effectiveness of the surfactant-polymer formulation in terms of enhancing oil recovery.

\section{Conclusions}

Didodecylmethyl hydroxyl sulfobetaine was synthesized by reacting didodecylmethyl amine with sodium 2-hydroxy-3-chloro propanesulfate. Its structure was confirmed by IR and ESI-MS spectra. The didodecylmethyl hydroxyl sulfobetaine could reduce the interfacial tension between Dagang oil and the formation water to ultra-low values in the presence of $1,500 \mathrm{mg} / \mathrm{L}$ of polymer or absence of the polymer. When in the presence of polymer, the surfactant-polymer system could reduce that the interfacial tension to ultra-low values even was aged more than 14 days. Core flood tests indicated that $16.89 \%$ additional oil was recovered by surfactant-polymer flooding with the surfactants and polymer solutions without using alkali.

Acknowledgments The authors are grateful for the financial support from key technical research and application program of increasing and stable 8 million tons of oil production in Huabei oil field. The grant no. Is 2014E-35-7.

Open Access This article is distributed under the terms of the Creative Commons Attribution License which permits any use, distribution, and reproduction in any medium, provided the original author(s) and the source are credited.

\section{References}

Aoudia M, Shibli MN, Al-Kasimi LH, Al-Maamari R, Al-bermani A (2006) Novel Surfactants for Ultralow Interfacial Tension in a Wide Range of Surfactant Concentration and Temperature. J Surfactants Deterg 9:287-293

Bagci S, Kok VM, Turksoy U (2000) Determination of formation damage in limestone reservoirs and its effect on production. J Petrol Sci Eng 28:1-12

Ball JT, Surkalo H (1990) A new variation of chemical EOR and its economic potential: the ASP process. Energy Source 12:121-130

Berger PD, Lee CH (2006) Improved ASP process using organic alkali. SPE/DOE Symposium on Improved oil recovery, Tulsa, Apr 22-26

Cheng JC, Xu DP, Bai WG (2008) Commercial test of ASP Flooding in Daqing Oil Field. Abu Dhabi International Petroleum Exhibition and Conference, Abu Dhabi, November 3-6

Cui ZG, Du XR, Pei XM, Jiang JZ, Wang F (2012) Synthesis of didodecylmethylcarboxyl betaine and its application in surfactant-polymer flooding. J Surfactants Deterg 15:685-694

Deborah AP, Philip BL (1990) Surfactant-enhanced low-pH alkaline flooding. SPE Reserv Eval Eng 5:327-332

Feng AZ, Zhang GC, Ge JJ, Jian P (2012) Study of surfactantpolymer flooding in heavy oil reservoirs. SPE Heavy Oil Conference, Calgary, Jun 12-14

Flaaten AK, Nguyen QP, Zhang JY, Mohammadi H (2010) Alkaline/ surfactant/polymer chemical flooding without the need for soft water. SPE J 15:184-196

Gupta R, Mohan K, Mohanty KK (2009) Surfactant screening for wettability alteration in oil-wet fractured carbonates. SPE Annual Technical Conference and Exhibition, New Orleans, Oct 4-7

Hill HJ, Reisberg J (1973) Aqueous surfactant systems for oil recovery. J Petrol Technol 25:186-194

Hirasak GJ, Miller CA, Puerto M (2011) Recent advances in surfactant EOR. SPE J 16:889-907 
Hou JR, Liu ZC, Zhang SF, Yue XA, Yang JZ (2005) The role of viscoelasticity of alkali/surfactant/polymer solutions in enhanced oil recovery. J Petrol Sci Eng 47:219-235

Iglauer S, Wu Y, Shuler PJ, Blanco M, Tang Y, Goddard WA (2004) Alkyl polyglycoside surfactants for improved oil recovery. SPE/ DOE Symposium on Improved Oil Recovery, Tulsa, Apr 17-21

Johnson CE (1957) Evaluation of surfactants for oil field flooding. J Am Oil Chem Soc 34:209-214

Kang WL, Liu Y, Qi BY, Liao GZ (2000) Interactions between alkali/ surfactant/polymer and their effects on emulsion stability. Colloid Surf A 175:243-247

Krumrine PH, Mayer EH, Brock GF (1985) Scale Formation During Alkaline Flooding. J Petrol Technol 37:1466-1474

Li XS (2009) Study on Foam Combination Flooding System without Alkali and Low Interfacial Tension. J Oil Gas Technol 31:130-135

Li Y, Duan YZ, Zhang K (2010) Effect of Alkanolamide on Interfacial Tension and Loss of Petroleum Sulfonates for Enhanced Oil Recovery.J Disper. Sci Technol 31:722-726

Li N, Zhang GC, Ge JJ, Zhang L, Liu XL (2012) Ultra-low interfacial tension between heavy oil and betaine-type amphoteric surfactants. J Disper Sci Technol 33:258-264

Meng LW, Kang WL, Guo LM (2010) Study on interfacial tension between alkanolamide surfactants of different carbon structure and daqing crude oil recovery. Asia-Pacific Power and Energy Engineering Conference, Chengdu, Mar 28-31

Miller DJ, Halasz SV, Schmidt M, Holst A, Pusch G (1991) Surfactant systems for enhanced oilrecovery at high salinities. J Petrol Sci Eng 6:63-72
Qu GM, Cheng JC, Wei JJ, Yu T, Ding W, Luan HX (2011) Characterization and surface properties of series sulfobetaine. J Surfactants Deterg 14:31-35

Rudin J, Wasan DT (1992) Mechanisms for lowering of interfacial tension in alkali/acidic oil systems: effect of added surfactant. Ind Eng Chem Res 31:1899-1906

Samanta A, Bera A, Ojha K, Mandal A (2010) Effects of alkali, salts, and surfactant on rheological behavior of partially hydrolyzed polyacrylamide solutions. J Chem Eng Data 55:4315-4322

Scott GR, Collins HN, Flock DL (1965) Improving waterflood recovery of viscous crude oils by chemical control. J Can Petrol Technol 4:243-251

Shinoda K, Shibata Y (1986) Principles for the attainment of minimum oil-water interfacial tension by surfactants:the characteristics of organized surfactant phase. Colloids Surf 19:185-196

Xiong S, Liu X, Liu W, He Y, Ruan X (2009) Petroleum sulfonates as oil displacement agents and application to Gudao oil field. Petrol Sci Technol 27:357-367

Yu HW, Chen TP, Gao M, Liu JS, Liu JJ (2011) Estimates of surfactant concentration used for eor in Daqing oilfield. SPE Enhanced Oil Recovery Conference, Kuala Lumpur, Jul 19-21

Zhao L, Li AF, Chen K, Tang JJ, Fu SS (2012) Development and evaluation of foaming agents for high salinity tolerance. J Petrol Sci Eng 81:18-23

Zhu YY, Zhang Y, Niu JL, Liu WD, Hou QF (2012) The research progress in the alkali-free surfactant-polymer combination flooding technique. Petrol Explor Dev 39:371-376 